\title{
Depression and anxiety in people with inflammatory bowel disease
}

\author{
L M Kurina, M J Goldacre, D Yeates, L E Gill
}

\begin{abstract}
Study objective-To determine whether depression or anxiety co-occurs with ulcerative colitis (UC) or Crohn's disease (CD) more often than expected by chance, and, if so, whether the mental disorders generally precede or follow the inflammatory bowel diseases (IBD).

Design-Nested case-control studies using a database of linked hospital record abstracts.

Setting-Southern England.

Main results-Both depression and anxiety preceded UC significantly more often than would be predicted from the control population's experience. The associations were strongest when the mental conditions were diagnosed shortly before UC, although the association between depression and UC was also significant when depression preceded UC by five or more years. Neither depression nor anxiety occurred before CD more often than expected by chance. However, depression and anxiety were significantly more common after $C D$; the associations were strongest in the year after the initial record of CD. UC was followed by anxiety, but not by depression, more often than expected by chance and, again, the association was strongest within one year of diagnosis with UC.

Conclusions-The concentration of risk of depression or anxiety one year or less before diagnosis with UC suggests that the two psychiatric disorders might be a consequence of early symptoms of the as yet undiagnosed gastrointestinal condition. The data are also, however, compatible with the hypothesis that the psychiatric disorders could be aetiological factors in some patients with UC. Most of the excess anxiety or depression diagnosed subsequent to diagnosis of IBD occurs during the year after IBD is diagnosed and the probable explanation is that the mental disorders are sequelae of IBD.

(F Epidemiol Community Health 2001;55:716-720)
\end{abstract}

Unit of Health-Care Epidemiology, Institute of Health Sciences, University of Oxford, Old Road, Oxford OX3 7LF, UK

Correspondence to: Dr Goldacre

(michael.goldacre@

dphpc.ox.ac.uk)

Accepted for publication 13 May 2001
The causes of inflammatory bowel disease (IBD) - ulcerative colitis (UC) and Crohn's disease (CD) - are unknown. For decades, some clinicians have held the view that IBD, and UC in particular, may, in part, be psychosomatic conditions. ${ }^{1-3}$ Indeed, research aimed at identifying IBD "personality types" and psychosomatic components of IBD is still undertaken. ${ }^{4}$ It is clear that neurotic symptoms are manifest in some patients with IBD, but it is much less clear that neurotic disorders play an aetiological part in IBD.
There is a reasonably consistent body of work that shows that neurotic disorders, and depression in particular, co-occur with CD more often than expected by chance. ${ }^{6-11}$ This work has not, however, shown a clear temporal sequence between neurotic disorders and CD - that is, the neurotic disorders do not necessarily precede CD as would be the case if they contributed to the aetiology of CD.

Findings on the association between neurotic disorders and UC have been inconsistent. ${ }^{61213}$ A systematic review of the literature on UC and psychiatric illness and a detailed analysis of the seven high quality studies published up to 1989 led North et al ${ }^{14}$ to conclude that there was no association between the two conditions. Results of more recent studies, however, have suggested that UC patients do suffer from psychiatric illness, and from depression and anxiety in particular, at a higher rate than either the general population or groups of patients with other types of chronic illness. ${ }^{11} 1516$

There are several possible explanations for the co-occurrence of depression or anxiety and IBD. The two psychiatric disorders might predispose people to IBD or, conversely, IBD might predispose people to depression or anxiety. IBD and the psychiatric disorders might share a common environmental, behavioural or genetic aetiology. Depression or anxiety might also be associated with IBD through a related factor such as treatment. Finally, the two conditions might co-occur as a result of confounding. We have used linked medical statistics from the Oxford Record Linkage Study (ORLS) to determine whether depression or anxiety cooccurs with IBD more often than expected by chance and, if so, what the diagnostic sequence is.

\section{Methods}

The ORLS database includes anonymised statistical abstracts of records of general hospital admissions (including day cases), inpatient psychiatric care and death certificates in a defined population in southern England. ${ }^{17}$ The area covered had a population of about 350000 people in 1963; it expanded to cover 1.9 million from 1975 and 2.5 million (all eight health districts in the former Oxford health region) from 1987. From 1971 to 1994, the ORLS also included records of non-inpatient psychiatric service contacts (for example, outpatient care and home visits by psychiatrists) for the county of Oxfordshire. We analysed the associations, described below, with and without the non-inpatient cases. Apart from reducing numbers and weakening statistical power, the pattern of findings was 
Table 1 Prior depression or anxiety in people with inflammatory bowel disease: observed numbers of people with inflammatory bowel disease and prior depression or anxiety, expected numbers, the ratio of observed to expected, and $95 \%$ confidence intervals

\begin{tabular}{|c|c|c|c|c|c|}
\hline First condition & Second condition & $\begin{array}{l}\text { Interval between first } \\
\text { and second conditions }\end{array}$ & Observed & Expected & $O / E(95 \% C I)$ \\
\hline Depression & Ulcerative colitis & $\begin{array}{l}\text { all time intervals } \\
<1 \text { year } \\
1-4 \text { years } \\
5+\text { years }\end{array}$ & $\begin{array}{l}92 \\
16 \\
21 \\
55\end{array}$ & $\begin{array}{l}65.8 \\
7.5 \\
20.8 \\
37\end{array}$ & $\begin{array}{l}1.40(1.13,1.72) \\
2.14(1.22,3.49) \\
1.01(0.62,1.55) \\
1.49(1.12,1.93)\end{array}$ \\
\hline Anxiety & Ulcerative colitis & $\begin{array}{l}\text { all time intervals } \\
<1 \text { year } \\
1-4 \text { years } \\
5+\text { years }\end{array}$ & $\begin{array}{l}35 \\
7 \\
9 \\
19\end{array}$ & $\begin{array}{l}23.5 \\
2.3 \\
7 \\
14.2\end{array}$ & $\begin{array}{l}1.49(1.04,2.07) \\
3.04(1.20,6.29) \\
1.29(0.58,2.45) \\
1.34(0.81,2.09)\end{array}$ \\
\hline Depression & Crohn's disease & $\begin{array}{l}\text { all time intervals } \\
<1 \text { year } \\
1-4 \text { years } \\
5+\text { years }\end{array}$ & $\begin{array}{l}50 \\
9 \\
14 \\
27\end{array}$ & $\begin{array}{l}43.9 \\
5.4 \\
14.9 \\
23.5\end{array}$ & $\begin{array}{l}1.14(0.85,1.5) \\
1.66(0.75,3.16) \\
0.94(0.51,1.58) \\
1.15(0.76,1.67)\end{array}$ \\
\hline Anxiety & Crohn's disease & $\begin{array}{l}\text { all time intervals } \\
<1 \text { year } \\
1-4 \text { years } \\
5+\text { years }\end{array}$ & $\begin{array}{l}20 \\
2 \\
6 \\
12\end{array}$ & $\begin{array}{l}15.5 \\
2.1 \\
4.8 \\
8.6\end{array}$ & $\begin{array}{l}1.29(0.79,2.0) \\
0.96(0.09,3.54) \\
1.25(0.45,2.74) \\
1.40(0.72,2.45)\end{array}$ \\
\hline
\end{tabular}

similar when the non-inpatient cases were excluded. For simplicity, we report here on the results that include both inpatient and noninpatient cases. Stratification for district of residence and year of occurrence of the case or control event was used to control for differences in data collection over the time period. All diagnostic data are coded in the ORLS using the International Classification of Diseases (ICD) coding system; see appendix for the ICD codes used for the conditions in this study. The period covered by the analyses in this paper was 1 January 1963 to 31 March 1999 (ORLS file 5v1c).

SELECTION OF CLINICAL CONDITIONS

We did a series of nested case-control studies to test whether UC or CD co-occurred with depression or anxiety more often than expected by chance. ${ }^{18}$ In the first set of analyses, the "cases" comprised all those persons with UC $(\mathrm{n}=7268)$ or $\mathrm{CD}(\mathrm{n}=5231)$ recorded on a hospital admission record or death certificate. The prior "exposure" condition was either depression or anxiety, recorded as a diagnosis on a hospital admission record or psychiatric service contact record before the first admission for the case condition. In the second set of analyses, the cases comprised all those persons with depression $(n=41324)$ or anxiety ( $n=$ 12687 ) recorded on a hospital admission record or a non-inpatient psychiatric service contact record. The latter non-inpatient records accounted for $25 \%$ of the cases of depression and $40 \%$ of the cases of anxiety. In these analyses, the prior exposure condition was either UC or CD.

The "controls" for both sets of analyses were people who had been admitted to hospital for any one of a wide range of minor medical or surgical conditions (listed in the appendix), none of which was related in any obvious way to the conditions of interest in this study. Approximately 800000 persons were included as controls for each comparison. We scrutinised the results of the case-control comparisons for each control group individually, as well as overall, to check that no individual control group gave results that looked aberrant compared with others.

Selection procedures for dealing with multiple diagnoses per admission and multiple admissions per person were as follows. Any given hospital admission record may include more than one diagnosis or operation for each admission. We classified people as cases if the case condition was recorded at any position on the hospital record. In contrast, people were only classified as controls if the control diagnosis or operation was recorded as the principal one on the record. The logic of this was to avoid selecting as controls people with other, more major conditions. People with both a case condition and a control condition were selected as cases (and removed from the control group). When a person had more than one admission for a given condition, the date of the first admission was selected as the date of the "index" event. Finally, to reduce the possibility of Berkson's bias, ${ }^{19}$ we excluded anyone whose first record of admission for a case or control condition also contained a diagnosis for the exposure condition.

\section{CALCULATION OF EXPECTED VALUES}

We used a method analogous to indirect standardisation to calculate the expected number of exposed cases, based on the experience of the controls. Firstly, we determined the occurrence of the exposure condition in the control group, calculating rates of exposure stratified by age in five year bands, sex, district of residence and year of occurrence of the case or control event. Next, these rates were applied to the case population to generate an expected number of cases with the exposure condition. The observed number of cases with the exposure condition was divided by the expected number to give an estimate of the relative risk. A Poisson distribution was assumed for the observed values, and confidence intervals for the relative risks were calculated accordingly. ${ }^{20}$

\section{Results}

Fifty one per cent of the cases with UC and $59 \%$ of the cases with CD were female. Sixty 
Table 2 Prior inflammatory bowel disease in people with depression or anxiety: observed numbers of people with depression or anxiety and prior inflammatory bowel disease, expected numbers, the ratio of observed to expected, and $95 \%$ confidence intervals

\begin{tabular}{|c|c|c|c|c|c|}
\hline First condition & Second condition & $\begin{array}{l}\text { Interval between first } \\
\text { and second conditions }\end{array}$ & Observed & Expected & $O / E(95 \% C I)$ \\
\hline Ulcerative colitis & Depression & $\begin{array}{l}\text { all time intervals } \\
<1 \text { year } \\
1-4 \text { years } \\
5+\text { years }\end{array}$ & $\begin{array}{l}70 \\
25 \\
20 \\
25\end{array}$ & $\begin{array}{l}57.6 \\
10.5 \\
17.9 \\
29.3\end{array}$ & $\begin{array}{l}1.21(0.95,1.54) \\
2.39(1.54,3.53) \\
1.12(0.68,1.73) \\
0.85(0.55,1.26)\end{array}$ \\
\hline Ulcerative colitis & Anxiety & $\begin{array}{l}\text { all time intervals } \\
<1 \text { year } \\
1-4 \text { years } \\
5+\text { years }\end{array}$ & $\begin{array}{l}29 \\
10 \\
5 \\
14\end{array}$ & $\begin{array}{l}17.2 \\
2.6 \\
5.9 \\
8.7\end{array}$ & $\begin{array}{l}1.68(1.13,2.42) \\
3.79(1.80,6.99) \\
0.85(0.27,2.0) \\
1.61(0.88,2.7)\end{array}$ \\
\hline Crohn's disease & Depression & $\begin{array}{l}\text { all time intervals } \\
<1 \text { year } \\
1-4 \text { years } \\
5+\text { years }\end{array}$ & $\begin{array}{l}74 \\
25 \\
21 \\
28\end{array}$ & $\begin{array}{l}44.4 \\
4.7 \\
15.6 \\
24.1\end{array}$ & $\begin{array}{l}1.67(1.31,2.09) \\
5.27(3.41,7.79) \\
1.35(0.83,2.06) \\
1.16(0.77,1.68)\end{array}$ \\
\hline Crohn's disease & Anxiety & $\begin{array}{l}\text { all time intervals } \\
<1 \text { year } \\
1-4 \text { years } \\
5+\text { years }\end{array}$ & $\begin{array}{l}21 \\
7 \\
3 \\
11\end{array}$ & $\begin{array}{l}13.6 \\
1.3 \\
4.8 \\
7.4\end{array}$ & $\begin{array}{l}1.54(0.95,2.36) \\
5.26(2.09,10.91) \\
0.62(0.12,1.84) \\
1.49(0.74,2.66)\end{array}$ \\
\hline
\end{tabular}

four per cent of the cases with depression and $62 \%$ of the cases with anxiety were female. Analysing the data in five year age bands, the modal age at first diagnosis with UC or CD was between 35 and 39 and 25 and 29 years of age, respectively. The modal age at first diagnosis with either depression or anxiety was between 30 and 34 years of age.

Both depression and anxiety preceded UC significantly more often than would be predicted from the control population's experience (table 1). The association was strongest when the two psychiatric disorders and UC were diagnosed in the same year, although the association between depression and UC was also significant when depression preceded UC by five or more years. Neither depression nor anxiety preceded CD more often than expected by chance, although there were fewer cases with CD than with UC (table 1).

UC was followed by anxiety, but not by depression, more often than expected by chance; the association was strongest during the year after the initial record of UC. CD was followed by both depression and anxiety at a higher than expected rate (table 2) and, again, the association was strongest during the year after the initial record of CD (table 2).

\section{Discussion}

There are several alternative strategies for studying the hypothesis that psychiatric disorders may predispose people to IBD. Most studies to date have been interview-based, case-control studies of prevalent IBD cases. With this study design, however, it can be difficult to establish the time sequence of events reliably-whether the psychiatric condition clearly preceded the IBD-particularly if the onset of the conditions was distant in time. It may also be difficult to avoid responder bias; it is possible, for example, that patients with bowel disease may report previous psychiatric illness more readily than controls. An interview-based, case-control study of incident cases interviewed soon after the onset of IBD would reduce the first problem, though not necessarily the second, but it would take considerable time for new cases to accrue. A cohort study would avoid both problems by taking, as its starting point, people with psychiatric disorders (or perhaps people whom the investigators would test psychometrically), but the rarity of IBD would make such a follow up study formidably large and costly. These considerations make a record linkage study attractive.

A psychosomatic aetiology for IBD would lead us to expect a diagnosis of depression or anxiety well in advance of the diagnosis of IBD. We found that a prior diagnosis of depression or anxiety was not significantly more common in patients with CD than in the control population, although the upper limit of the $95 \%$ confidence interval for depression was 1.5 and for anxiety was 2.0. Prior depression and anxiety were both significantly more common in patients with UC than in the control population, although the overall relative risks were modest at 1.4 and 1.5 , respectively, and the upper limits of the $95 \%$ confidence intervals were 1.7 for depression and 2.1 for anxiety. The strongest association between either anxiety or depression and UC occurred when the diagnoses were separated by less than one year. There are several possible explanations for this result. Firstly, the onset of depression or anxiety might be causally related to the development of UC. Secondly, perhaps people become depressed or anxious as a result of an existing but as yet undiagnosed bowel condition. Finally, it is possible that some patients were initially diagnosed with IBD in general practice, suffered from depression or anxiety as a reaction to living with the IBD, and subsequently required admission to hospital for IBD thereby being recorded as having IBD "after" the diagnosis of the psychiatric disorder.

It is difficult to distinguish among these three possibilities definitively, although if the excess of depression or anxiety during the year before diagnosis with UC could be attributed largely to a reaction to UC, which was either undiagnosed or diagnosed without requiring admission to hospital, we might have expected a similar result for CD. Furthermore, prior 
depression was also significantly more common in patients with UC than in controls when five or more years separated the diagnoses. This result suggests that the aetiology of UC may involve a psychoneuroimmunological component. Perhaps a depression related suppression of immune system function predisposes some patients to IBD. ${ }^{21}$ The association is not strong, with a relative risk of less than 2 , and it is therefore unlikely that depression plays an important aetiological part in most cases of UC. However, on balance, these data do lend some credence to the hypothesis that depression might predispose some peope to UC, perhaps interacting with existing but as yet unidentified genetic or environmental risk factors.

When considering the reverse time sequence-IBD followed by depression or anxiety-we found that CD was followed by both depression and anxiety more commonly than would be expected by chance. These associations were particularly strong within the first year of diagnosis with CD, when the data suggest a fivefold increase in risk, although the numbers are fairly small. UC was followed by anxiety, but not depression, more commonly than expected by chance, but as with $\mathrm{CD}$, the association was strongest (a nearly fourfold increase in risk) when the conditions were diagnosed within the same year. The most probable explanation for this result is that the depression or anxiety is a reaction to the IBD — caused either by the physical symptoms of the IBD itself or perhaps by the side effects from, for example, corticosteroids, a common treatment for IBD.

The ORLS database consists largely of inpatient and day case admissions, although non-inpatient records of psychiatric care were collected and incorporated into the database for the county of Oxfordshire from 1971 to 1994. Most people with UC or CD are likely to have been admitted to hospital at least once in the course of their illness. However, many people with anxiety or depression will not have received specialist psychiatric care, either on an inpatient or an outpatient basis. Although some studies have linked personality traits, such as neuroticism and introversion, with IBD, ${ }^{516}$ we have no information on the personality traits of people in our database and so our study is limited to anxiety and depression as defined by ICD diagnoses on hospital admission and psychiatric outpatient records. Even for those who were admitted for the conditions of interest here, admissions will have been missed when they occurred outside the area of, or before the time period covered by, the ORLS. Accordingly, the absolute levels of disease occurrence identified by us are substantially underestimated. However, the relative rates of occurrence, comparing cases and controls, should give a valid estimate of whether the pairs of diseases occur together more often than expected.

One unfortunate omission from routine medical statistics is the date of disease onset. This prevents the accurate quantification of disease incidence by date. ${ }^{22}$ When people in the
KEY POINTS

- Depression and anxiety are significantly more common in people with inflammatory bowel disease (IBD) than in controls.

- Relative risks for the mental disorders preceding IBD suggest that any role of the first in the aetiology of the second is small.

- However, risk of depression or anxiety is high during the year after diagnosis of IBD.

- Clinicians should be aware that these mental disorders may occur as sequelae of IBD.

ORLS database have more than one admission for the case condition (or exposure condition), the date of the first admission is selected as the date of the "index" event (see Methods). This date is only an approximation of the incidence date. If, however, we assume that migration rates are similar between the cases and controls our estimates of relative risk should be unbiased in this regard.

It is possible that people with neurotic disorders may seek health care for minor conditions more frequently than other people. ${ }^{23}{ }^{24}$ If this occurred with the control conditions, it would inflate the occurrence of depression and anxiety in the control group, inflate the expected value calculated for the IBD cases, and therefore tend to reduce any real association between the psychiatric conditions and IBD. Conversely, people with IBD might be recognised as being depressed or anxious more readily than other people because of more frequent contact with their GP-thus producing a form of ascertainment bias in our data and inflating the association between prior IBD and subsequent depression or anxiety. It seems probable, however, that most of such additional health care-potentially skewing either the controls' experience or that of the IBD caseswould be sought in general practice, and not require hospital admission, which would leave our results largely unaffected. Our observations of depression or anxiety are based on inpatient hospital admission records (general or psychiatric) or outpatient psychiatric hospital records, suggesting that the episodes of depression or anxiety occurring in these patients are sufficiently severe as to require treatment beyond the scope of general practice.

Our data are largely consistent with the results of the most recent studies on this topic, which have found depression and/or anxiety to be more common in patients with IBD than in the general population or in patient groups with other chronic diseases. ${ }^{11}{ }^{15} 16$ Our results indicate that depression and anxiety, at least at the level of severity to require specialist psychiatric care, have only a small effect, if any, on the aetiology of IBD; the evidence for such an effect is stronger for UC than for CD. Patients with each type of IBD, however, are at an increased risk, particularly within the first year of diagnosis of IBD, of subsequent depression 
or anxiety. Clinicians, therefore, should be aware of these as possible sequelae of IBD.

We thank Glenys Bettley and Myfanwy Griffith for their help in building the linked files and Penelope Lee for comments on the manuscript.

Funding: The Unit of Health-Care Epidemiology is funded by the South East Regional Office of the National Health Service Executive.

Conflicts of interest: none.

\section{Appendix}

1 The ICD codes used for the case and exposure conditions in this study were as shown in table A1.

Table A1

\begin{tabular}{cllll}
\hline Condition & ICD 7 & ICD 8 & ICD 9 & ICD 10 \\
\hline $\begin{array}{c}\text { Crohn's } \\
\text { disease }\end{array}$ & 572.0 & 563.0 & $555.0-555.2, \mathrm{~K} 50$ \\
$\begin{array}{c}\text { Ulcerative } \\
\text { colitis }\end{array}$ & 572.2 & 563.1 & 556 & $\mathrm{~K} 51$ \\
$\begin{array}{c}\text { Depression } \\
\text { 314, }\end{array}$ & 300.4, & 300.4, & $\mathrm{~F} 32.0-2, \mathrm{~F} 32.8-9$, \\
& 790.2 & 790.2 & $309.0,311$ & $\mathrm{~F} 33.0-2, \mathrm{~F} 33.4$, \\
Anxiety & 310 & 300.0 & 300.0 & F33.8-9 \\
\hline
\end{tabular}

2 The control conditions used in this study were as follows, using the terminology of ICD9 and the Office of Population Censuses and Surveys (OPCS) Classification of Surgical Operations, Third Revision: sebaceous cyst; disorders of tooth development and eruption; diseases of hard tissues of teeth; deflected nasal septum; nasal polyps; varicose veins of lower extremities; haemorrhoids; acute respiratory infections; otitis media; otitis externa; strabismus; cataract; inguinal hernia; diseases of nail; internal derangement of knee; bunion; contraceptive management; dilation of cervix and curettage of uterus; fracture of upper limb and lower limb; dislocations, sprains, and strains; superficial injury and contusion; total hip replacement; total knee replacement; tonsillectomy and adenoidectomy.

1 Gelder M, Gath D, Mayou R. Oxford textbook of psychiatry. 2nd ed. Oxford: Oxford University Press, 1988.

2 Moser G. Ulcerative colitis and psychosocial factors. Ital $\mathcal{F}$ Gastroenterol Hepatol 1997;29:387-94.

3 Ramchandani D, Schindler B, Katz J. Evolving concepts of psychopathology in inflammatory bowel disease. Med Clin North Am 1994;78:1321-30.
4 Smith GJW, van der Meer G, Ursing B, et al. Psychological profile of patients suffering from Crohn's disease and
ulcerative colitis. Acta Psychiatr Scand 1995;92:187-92.

5 Tocchi A, Lepre L, Liotta G, et al. Familial and psychological risk factors of ulcerative colitis. Ital $\mathcal{f}$ Gastroenterol Hepatol 1997;29:395-8.

6 Andrews H, Barczak P, Allan RN. Psychiatric illness in patients with inflammatory bowel disease. Gut 1987;28: 1600-4.

7 Helzer JE, Chammas S, Norland CC, et al. A study of the association between Crohn's disease and psychiatric illness. Gastroenterology 1984;86:324-30.

8 Schwartz RA, Schwartz IK. Psychiatric disorders associated with Crohn's disease. Int $\mathcal{F}$ Psychiatry Med 1982;12:67-73.

9 Tarter RE, Switala J, Carra J, et al. Inflammatory bowel disease: psychiatric status of patients before and after disease onset. Int f Psychiatry Med 1987;17:173-81.

10 Walker EA, Roy-Byrne PP, Katon WJ, et al. Psychiatric illness and irritable bowel syndrome: a comparison with inflammatory bowel disease. Am f Psychiatry 1990;147: inflammator.

11 Addolorato G, Capristo E, Stefanini GF, et al. Inflammatory bowel disease: a study of the association between anxiety and depression, physical morbidity, and nutritional status. Scand $\mathcal{F}$ Gastroenterol 1997;32:1013-21.

12 Helzer JE, Stillings WA, Chammas S, et al. A controlled study of the association between ulcerative colitis and psychiatric diagnoses. Dig Dis Sci 1982;27:513-18.

13 Mendeloff AI, Monk M, Siegel CI, et al. Illness experience and life stresses in patients with irritable colon and with ulcerative colitis. $N$ Engl f Med 1970;282:14-7.

14 North CS, Clouse RE, Spitznagel EL, et al. The relation of ulcerative colitis to psychiatric factors: a review of findings and methods. Am F Psychiatry 1990;147:974-81.

15 Magni G, Bernasconi G, Mauro P, et al. Psychiatric diagnoses in ulcerative colitis. A controlled study. Br fPsydiagnoses in ulcerative colitis.
chiatry 1991;158:413-15.

16 Robertson DAF, Ray J, Diamond I, et al. Personality profile and affective state of patients with inflammatory bowel disease. Gut 1989;30:623-6.

17 Goldacre MJ, Simmons H, Henderson J, et al. Trends in episode based and person based rates of admission to hospital in the Oxford record linkage study area. BMf 1988;296:583-5.

18 Goldacre M, Kurina L, Yeates D, et al. Use of large medical databases to study associations between diseases. QFM 2000;93:669-75.

19 Berkson J. Limitations of the application of fourfold table analysis to hospital data. Biometrics Bulletin 1946;2:47-53.

20 Esteve J, Benhamou E, Raymond L. Statistical methods in cancer research. Lyon: International Ageny for Research on Cancer, 1994

21 Stein M. Stress, depression, and the immune system. 7 Clin Psychiatry 1989;50 (suppl):35-40

22 Goldacre M, Shiwach R, Yeates D. Estimating incidence and prevalence of treated psychiatric disorders from and prevalence of treated psychiatric disorders from routine statistics: the example of schizophrenia in Oxforc
shire. 7 Epidemiol Community Health 1994;48:318-22.

23 Henk HJ, Katzelnick DJ, Kobak KA, et al. Medical costs attributed to depression among patients with a history of high medical expenses in a health maintenance organization. Arch Gen Psychiatry 1996;53:899-904.

24 Manning WG, Wells KB. The effects of psychological distress and psychological well-being on use of medicalservices. Med Care 1992;30:541-53. 